\title{
O ACOMPANHAR NA DESINSTITUCIONALIZAÇÃO
}

\author{
TAKING CARE OF DEINSTITUTIONALIZATION
}

Elisabetta Laganà ${ }^{1}$

Elisabetta Laganà. O acompanhar na desinstitucionalizaação. Rev Bras Crescimento Desenvolv Hum. 2010; 20(1): 42-50

\section{Resumo}

São descritos os propósitos e a organização da Conferência Nacional de Voluntariado da Justiça Italiana. Em particular são destacados os fundamentos do trabalho do voluntariado: a salvaguarda dos direitos, a responsabilidade, a gratuidade, o valor da relação. Perante a despersonalização da instituição, a relação entre os voluntários e os detentos, nos manicômios judiciários e nos cárceres, oferece possibilidade de um reconhecimento importante da subjetividade da pessoa. Além disso o voluntariado oferece respostas concretas para integração na sociedade e contribui para reconstruir uma rede social à volta do sujeito.

Algumas possibilidades concretas para ultrapassar o hospital psiquiátrico judiciário na Itália começam a surgir, nos últimos tempos, através do projeto legislativo de Reforma do Código Penal e através da passagem da um sistema privado de saúde carcerária a um sistema único gerenciado pelo Ministério da Saúde. Ponto estratégico tornou-se o envolvimento direto das regiões (os estados) na gestão sanitária dos cárceres e dos manicômios judiciários.

Palavras-chave: voluntariado; direitos dos detentos; relação terapêutica; hospital psiquiátrico judiciário; saúde carcerária.

\begin{abstract}
The author describes the mission and the organization of Italian Justice Conference on Voluntary Service and emphasizes the principles of its activity: the safeguard of rights, the responsibility, the gratuitousness, the value of relation. Whereas the institution impoverishes, the relation between inmates and volunteers means improvement of persons, since without power involvement. Moreover the volunteers give concrete opportunities to reintegrate patients into society and to reconstruct a social network. Recently two events started and made close the overcoming of the Criminal Mental Hospitals in Italy: first the bill of a new penal code that abrogates the concept of mental patients social dangerousness, secondly the health system change from the Department of Justice to the Department of Health for Criminal Mental Hospitals and Prisons.
\end{abstract}

Key words: Voluntary Service; Inmates Rights; Psychotherapeutic Relation; Criminal Mental Hospital; Health in Prisons.

1 Psicóloga, psicoterapeuta, presidente da “Conferencia Nacional Voluntariado e Justicia” da Italia, presidente do SEAC (Coordenação Entes e Associações Voluntárias no Cárcere).

Endereço para correspondência: elisabetta.lagana@hotmail.it - Site: www.volontariatogiustizia.it. 


\section{INTRODUÇÃO}

A missão da Conferência Nacional de Voluntariado da Justiça Italiana. ${ }^{1}$

A Conferência tem como princípios norteadores:

1 Reconhece-se nos valores democráticos da Constituição Italiana, refere-se à Declaração Universal dos Direitos do Homem e da Criança e age à realização destes princípios;

2 Sua referência básica é a centralidade da pessoa, mesmo que submetida à disposição judicial;

3 Dedica-se aos direitos humanos de adultos e menores, à defesa da legalidade, ao suporte à pessoa, seja qual for o crime cometido.

\section{A Conferência:}

1 estima a detenção como a última escolha;

2 e age para: humanizar a pena, reduzir a detenção que habitualmente prejudica sobretudo os indivíduos mais fracos,

"territorializar" as sanções (quer dizer, manter uma proximidade entre $o$ detido e a família dele), ampliar a utilização das disposições alternativas à detenção, realizar experiências de mediação penal e de reconciliação entre os autores do crime e as vítimas porque, de fato, julga importante cuidar das vítimas do crime, pelo reconhecimento do sofrimento e do prejuízo causado a eles.

\section{ORGANIZAÇÃO}

A Conferência ${ }^{2}$ faz parte do universo filantrópico das instituições e associações que na Itália organizam-se espontaneamente a ní- vel local e central e que se fundam nos princípios de gratuidade, de solidariedade e de subsidiariedade (auxilio ao público).

A Conferência representa e coordena nove organizações nacionais partidárias, religiosas e laicas, espalhadas nas regiões italianas em numerosas organizações locais. A Conferência mantém relações oficiais com o Governo e as Instituições da Justiça a nível central. As relações com as instituições públicas estão sancionadas por protocolos rubricados com o Ministério da Justiça, com o Departamento da Administração Penitenciária e com a Delegação da Justiça dos Menores. Os protocolos reconhecem o valor social e a função do voluntariado como expressão de participação e de protagonismo na reintegração dos detentos, com igual dignidade aquelas da Administração da Justiça e de entidades políticas locais.

\section{Habitualmente o Voluntariado:}

1 visita os detidos nas cadeias e assume a resolução dos problemas legais, administrativos e familiares deles,

2 oferece aos detentos possibilidades de trabalho e de desenvolvimento de uma vida nutrida por sentimentos afetivos,

3 desenvolve um papel constante de informação e sensibilização da opinião pública com relação aos assuntos da Justiça,

4 contrasta os prejuízos e a idéia da pena (tipo) retributiva, aflitiva, marginalizante,

5 solicita e promove a colaboração das comunidades locais para recuperação dos sujeitos submetidos a medidas judiciais,

6 promove e põe em prática a cultura da legalidade e da prevenção, relativamente a qualquer ato criminoso. 


\section{O ARTIGO 27 DA CONSTITUIÇÃO ITALIANA}

\section{Porque é importante a voz do serviço voluntário no âmbito da Justiça?}

Porque a presença ativa da comunidade, representada pelo voluntariado ${ }^{3}$, consente oportunidades aos sujeitos "frágeis" e confirma que os direitos constitucionais são irrenunciáveis e imprescindíveis.

O artigo vinte e sete da Constituição Italiana declara que: "As penas não podem consistir em condições contrárias ao sentido da humanidade e devem propor-se à reeducação do condenado”. Este princípio é sancionado na lei da Reforma do Sistema Penitenciário de 1975, que sublinha a necessidade

1 de humanidade,

2 de respeito pela dignidade da pessoa,

3 de exclusão das discriminações,

4 de possibilidades de restrições só circunscritas a razões de disciplina e de ordem, plano individual de reinserção na sociedade e individualização do tratamento.

Nestes fundamentos inspira-se o Voluntariado da Justiça que remarca os princípios da Carta Constitucional por qualquer pessoa, em qualquer situação e que, de maneira especial, remarca, sobretudo, a salvaguarda dos direitos, a responsabilidade, o valor da relação e o voluntariado.

\section{SALVAGUARDA DOS DIREITOS}

A força da democracia se avalia no compromisso para opor-se às condições de disparidade contratual e no sistema de garantias para aqueles que se encontram em condições de vulnerabilidade social e econômica, como acontece com a maioria dos sujeitos submetidos a medidas judiciais. ${ }^{4} \mathrm{~A}$ salvaguarda dos direitos dos sujeitos vulneráveis funda-se no mesmo parâmetro da salvaguarda dos direitos de todos.

\section{RESPONSABILIDADE}

Julgamos o princípio da responsabilidade o eixo de nosso trabalho, um grande valor ao qual almejar, seja na responsabilidade individual, seja na responsabilidade coletiva. Existe uma dimensão política da responsabilidade relativamente a que cada um deve prestar contas: qualquer membro da comunidade é responsável por tudo o que está feito em seu nome. Por isso o voluntariado ${ }^{5}$ julga necessário denunciar o perigo de calar-se diante da "normalidade" da exclusão e à frente dos processos nos quais se reduz o papel da razão.

\section{A GRATUITIDADE}

A gratuidade do voluntariado significa assumir consciência de que existem relações fora da lógica do lucro e que estas relações funcionam diferentemente da lógica geral. ${ }^{6} \mathrm{O}$ gesto, que não prevê uma permuta econômica, conserva em si mesmo uma força extraordinária, cria uma partilha que consente alcançar o núcleo mais profundo da relação. O gesto gratuito individual constitui a matéria bruta para reconstruir a coesão social através da responsabilidade. Desta maneira a ética se torna elemento terapêutico para os indivíduos e para a sociedade.

\section{O VALOR DA RELAÇÃO}

Encontrar uma pessoa não significa reduzi-la a um juízo ou a um diagnóstico; encontrar uma pessoa põe em evidência a complexidade de uma história e abre a uma possibilidade de mudança. O encontro significa perguntarse por que o sujeito está ali e o que faltou para evitar que ele estivesse ali. Mas para inspirarnos ao valor da pessoa, sem preconceitos ou presunção, nós devemos estar sempre ao nível mais elevado do que é possível, do que a nossa 
humanidade permite. Só isto consente gestos coerentes e confiáveis.

Por isso devemos arriscar caminhos ainda não percorridos,

1 porque a humanidade é demasiadamente grande por estar encerrada em definições estanques,

2 porque as diferenças entre os sujeitos que têm muito e aqueles que não têm nada são inaceitáveis,

3 porque o crime não inclui toda a pessoa,

4 porque as relações entre o bem e o mal não se tornem preconceitos, e sim dúvidas para uma busca contínua do sentido da existência,

5 porque a vida de qualquer um não é um trajeto direito, porém è um trajeto sujeito a interrupções, descontinuidades e rupturas.

\section{NORMAS PENITENCIÁRIAS APROVADAS PELO COMITÊ DOS MINISTROS EUROPEUS}

Talvez possamos parecer loucos quando afirmamos que o cuidado, a tolerância, o respeito pelo homem e a natureza são idéias mais progressistas do que algumas proclamações políticas.

Ainda que nossas idéias não sejam ilusões, como demonstra o texto da lei "Novas normas penitenciárias”, aprovada pelo Comitê dos Ministros dos 46 Estados Europeus, em 11/ 01/2006 . A lei indica:

1 a detenção como última escolha,

2 declara os direitos humanos iguais independente da origem, censo, religião ou ideologia,

3 define com precisão as normas relativas aos lugares de detenção, a higiene, ao direito à informação e ao trabalho, as medidas sanitárias, incluindo a saúde mental e a prevenção dos suicídios.
Na realidade sabemos que estar detido não significa só estar desprovido da liberdade, significa sobretudo não ter possibilidade de escolha, estar submetido a regras contraditórias e incompreensíveis, fruto de sobreposição de numerosos regulamentos, disposições e ordens.

Por isso estas normas são claras e constituem o ponto de referência pelo Tribunal Europeu dos Direitos Humanos e pelo Comitê Europeu pela Prevenção da Tortura.

As regras afirmam:

1 que a falta de recursos não pode legitimar condições de detenção nocivas aos direitos fundamentais do detentos;

2 que cada detento sem roupa deve receber vestuário conforme o clima;

3 que a função essencial das autoridades penitenciais é velar por uma alimentação satisfatória dos detentos;

4 que é fundamental a importância da limpeza dos lugares e da higiene pessoal do detento: o Tribunal Europeu dos Direitos Humanos sublinha como a falta de higiene, a insalubridade, junto com a superpopulação, e devem ser julgados como tratamento degradante.

De fato, a seguir ao processo apresentado ao Tribunal Europeu dos Direitos Humanos por um detento contra as condições da própria detenção, o Governo da Itália foi recentemente condenado, por superlotação dos cárceres e pelos incômodos decorrentes, a ressarcir o detento.

\section{A REFORMA SANITÁRIA NO CÁRCERE}

O Decreto de Lei 230 de 1999 transferiu as funções sanitárias dos Institutos Penitenciários para o Sistema Sanitário Nacional ${ }^{7}$, e colocou as premissas para que finalmente fossem enfrentados com dignidade os graves problemas da saúde no cárcere e no Hospital 
Psiquiátrico Judiciário. Mas só com a Lei de abril de 2008 estabeleceram-se as condições para a passagem da um sistema privado de saúde carcerária a um sistema único de saúde, com os mesmos direitos à prevenção, ao tratamento e à reabilitação, com a mesma organização sanitária para os detentos e para os cidadãos em estado de liberdade.

Ao longo de muitos anos o Voluntariado, de maneira especial o Fórum Nacional para a Saúde Penitenciária, apontou os descumprimentos do Estado e impulsionou iniciativas para implementar forças disponíveis por uma reforma até a aprovação dela durante o Governo de Romano Prodi.

A Lei de abril de 2008 sancionou a transferência das competências e das responsabilidades do Ministério da Justiça ao Ministério da Saúde em todas as instituições Cárceres para Adultos, para Menores e Manicômios Judiciários ${ }^{8}$.

O Voluntariado tem sido envolvido diretamente neste projeto. Junto com a Direção de cada cárcere, com a Delegação Regional da Justiça Penitenciária9 , com os serviços sanitários, o Voluntariado está hoje ativando programas de prevenção primária e secundária e programas de educação em saúde nas prisões. Em particular o Voluntariado está sendo envolvido nos assuntos de saúde mental, de auto-mutilações e dos suicídios. ${ }^{10} \mathrm{~A}$ tarefa apresentase difícil porque a saúde física e mental chama para as responsabilidades sociais e institucionais, especificamente nos contextos onde se desenvolvem as intervenções. E quando o contexto é o próprio cárcere, há conflito insanável entre o tratamento habitual do detento e a possibilidade verdadeira de construir condições de saúde mental.

\section{A SAÚDE MENTAL NO CÁRCERE}

Então pode o Voluntariado produzir saúde mental no cárcere? ${ }^{11}$
Nós achamos que sim! O tempo na prisão, por exemplo, é inutilizado e inútil, mas através do encontro entre detento e voluntario o tempo pode tornar-se "tempo da escuta" e "tempo da palavra", repleto de potencialidades terapêuticas. ${ }^{12}$ Quando o encontro não é uma situação formal, a relação entre um preciso voluntário e uma precisa pessoa detida, num preciso instante, num preciso nível subjetivo e existencial, torna-se uma resposta dinâmica e eficaz. Por isso a motivação do voluntário revela-se elemento terapêutico: perante a despersonalização da instituição, a relação oferece uma possibilidade de re-singularidade. ${ }^{13}$

Uma importante pesquisa (Pietro Buffa, 2006-08) nos cárceres italianos pôs em evidência como a quantidade e a gravidade dos gestos auto-mutiladores dependia do alto ou baixo grau de tratamento. ${ }^{14}$ Por um alto grau de tratamento se se entende um número elevado de horas fora da cela, oportunidades de trabalho, de formação, de cultura, alto número de operadores, menor número de presos à espera de julgamento; por um baixo grau de tratamento se entende o contrário. Os resultados são previsíveis: onde há piores condições, há um maior número dos incidentes. ${ }^{15}$

Então como age o Voluntariado da Justiça?

Para entendê-lo, podemos considerar o papel dos voluntários frente a situações de automutilação. Os eventos necessitam sem dúvida de socorro médico, mas o sofrimento não é, em si, uma doença. Nos cárceres e nos Hospitais Psiquiátricos Judiciários ${ }^{16}$ precisamos de um aumento de rendimento dos serviços psicológicos e psiquiátricos, mas este leva apenas para a medicalização do mal estar. O que devem ser incrementados são, sobretudo os encontros, os cuidados, as possibilidades por não-profissionais de viver a experiência, de estar "dentro" da prisão. Sentir-se escutado tem um valor de tutela da subjetividade da pessoa, é um reconhecimento do indivíduo na sua dimensão de troca (considerando-se também que 
a escuta pode significar perceber sinais de automutilação e pode preveni-los).

A propósito o Departamento da Administração Penitenciária reconhece que naquelas divisões do cárcere e dos Hospitais Psiquiátricos Judiciários, onde se devolveram iniciativas do voluntariado, se reduziram significativamente momentos de tensão. ${ }^{17}$

Efetivamente o Voluntariado ativa não só a sua potencialidade de escuta, mas, sobretudo oferece respostas concretas para possibilidades de integração na sociedade: procura de alojamento, de trabalho, de contatos com as famílias dos detentos, etc.

\section{ULTRAPASSAR O HOSPITAL PSIQUIÁTRICO JUDICIÁRIO}

Um exemplo evidente da necessidade de implementação das políticas de re-integração é oferecido pela situação dos detentos nos Manicômios Judiciários ${ }^{18}$ : se estima que $60 \%$ dos internados poderiam ter alta se tivessem lugares de cuidado no território. Só agora com a passagem da saúde penitenciária ao sistema sanitário nacional torna-se possível ultrapassar estas instituições, realizando possibilidades de alta e de inclusão.

Esta tarefa, porém não pode ser cumprida só por psiquiatras. Dar alta a um paciente do Hospital Psiquiátrico Judiciário significa não só resolver uma patologia individual, mas reconstruir uma rede social à volta de uma pessoa: é um problema que envolve uma comunidade local inteira, é uma prova de democracia. ${ }^{19}$ Por isso o Voluntariado da Justiça desenvolve um papel crucial ativando a própria rede social. É o que acontece em algumas seções dos Hospitais Psiquiátricos Judiciários, especialmente naqueles onde é possível dar altas em prova.

Nesse caso os voluntários põem à disposição tempo, estruturas, lugares de acolhimento, recursos, trabalhando dentro e fora da instituição, em acordo com as Direções Penitenciárias e com o Juiz Tutelar. O poder decisório deste juiz para consentir alta alternativa à reclusão aumentou muito depois de uma recente disposição do Tribunal Superior Constitucional..$^{20}$ Mas precisaria legislar ainda mais para favorecer a solução do problema do Hospital Psiquiátrico Judiciário. Existe, por exemplo, um projeto legislativo de reforma do Código Penal - o projeto Pisapiaque prevê a abolição do conceito de "periculosidade social” e a aplicação de medidas de "tratamento e vigilância" por autores de crime não imputáveis. ${ }^{21}$ Neste projeto o prazo do tratamento não pode ser superior ao prazo da pena aplicável por aquela imputação. Indicam-se ainda mais algumas medidas entre as quais o juiz pode escolher a mais apropriada para o sujeito:

- a internação em moradias protegidas ou internação com objetivo de desintoxicação,

- a inclusão em comunidades terapêuticas,

- a liberdade vigiada associada ao tratamento terapêutico,

- a obrigação de estar sob vigilância no tratamento,

- o desempenho de atividades de trabalho o de atividades em proveito da coletividade,

- colocar sujeitos sob tutela dos serviços sócio-sanitários.

A presença dos voluntários ${ }^{22}$ representa uma possibilidade de abrir o cárcere ao controle da sociedade, representa o olhar critico da comunidade. A frente da lógica da dependência e do fechamento das instituições totais, que contrasta qualquer mudança, é a própria criação de numerosas e variadas trocas, é a lógica de trazer para "fora” (os pacientes e os detentos para medidas alternativas) e trazer para “dentro" (os cidadãos voluntários), que permite afetar a substância da instituição. 
Uma visita oficial, dois anos atrás, nos Manicômios Judiciais da Itália ${ }^{23}$ por uma delegação de políticos, associações e representantes do Fórum de Saúde Mental concluiu com esta afirmação: "Os Hospitais Psiquiátricos Judiciais devem fechar imediatamente. Eles representam uma tragédia silenciosa”. Os internados estavam em condições de degradação física e psicológica, fechados em si próprios, completamente ausentes, ocupados em gestos repetitivos. As celas estavam totalmente despojadas, desprovidas de qualquer mobília; havia ainda celas fortes. A maioria dos psiquiatras e dos enfermeiros trabalhava como emprego instável, a quantidade de horas do contrato eram insuficientes para garantir tratamentos apropriados. O pessoal de Polícia Penitenciária ${ }^{24}$ não tinha nenhuma formação profissional especifica. O montante do dinheiro por dia para a alimentação era irrisório (de um euro e cinqüenta centavos). Em muitas celas faltava papel higiênico e sabão; durante o inverno o aquecimento estava suspenso muitas vezes. A lista dos incômodos e da privação dos direitos era muito extensa.

Quando interrogados, os profissionais dos hospitais admitem que a situação é o colapso e julgam que mais da metade dos internados poderiam ser cuidados nos serviços territoriais de maneira apropriada e reabilitarem-se. Mas as "Aziende Sanitarie Locali”, responsáveis pela saúde no território, não têm intenção de assumir custos adicionais.

Semelhante a qualquer população das instituições totais, os sujeitos internados nos manicômios judiciais ${ }^{25}$ resultam de situações penalizadas do principio, sem poder social e econômico para contrastar os perigos mais dramáticos da vida deles. Desde sempre a diferença econômica, entre quem tem muito e quem tem pouco, decide a sorte e os direitos do sujeitos, determina a saúde e a salvaguarda da doença.

\section{AS AÇÕES EM ANDAMENTO}

Foi desenvolvido um programa para a superação do Hospital Psiquiátrico Judiciário e instituído um Comitê Paritário de Vigilância. ${ }^{26}$ As linhas de orientação e as ações do Comitê estão expressas na lei financeira de 2008. Ponto estratégico tornou o envolvimento direto das Regiões na gestão sanitária destas instituições. As Regiões, junto com o Departamento de Administração Penitenciaria adotaram um Plano Regional de intervenção no Hospital Psiquiátrico Judiciário, definem padrão, espaços, colocação das seções de observação, possível utilização do aprisionamento por drogaditos, definem objetivos quantitativos e qualitativos, cronograma e financiamento coordenado pelos programas de demissões.

Conseqüentemente as Regiões ativam programas de moradia, alternativas ao hospital, prevêem a re-utilização de camas no Hospital Psiquiátrico Judiciário e favorecem a passagem dos usuários para cuidados territoriais. Algumas Regiões (Emilia Romanha, Toscana) já realizaram a passagem dos profissionais da dependência do Ministério da Justiça para o Ministério da Saúde.

Para concluir, apesar de ainda termos muito por fazer, os resultados alcançados são bastante positivos.

\section{DE QUAL LADO?}

A nossa é uma época de revisionismo e de embrutecimento do clima político: à frente das dificuldades e das contradições da sociedade globalizada, fala-se na Itália, facilmente e por má-fé, de fracasso das reformas (reforma da saúde, da psiquiatria, do cárcere, da escola). Assim acontece que se ouve a pergunta: “De qual lado você se coloca?”, ${ }^{27}$

Colocamo-nos - é a nossa resposta! do lado dos direitos daqueles que não têm uma voz bastante forte, do lado dos fracos, para 
contrastar a desigualdade e a prática do poder que é forte com os fracos e fraco com os fortes. O cárcere e o manicômio judiciário, assim como hoje estão organizados, não curam, nem reabilitam; ao contrário, adoecem e desabilitam. Por isso o Voluntariado se opõe à idéia de ampliar o número das cadeias ${ }^{28}$, porque a internação, a separação, a marginalização tornaria a ser modalidade principal de disciplina da população, sem aumentar a segurança e a força das instituições, representando, pelo contrário, uma mudança humana, política, cultural negativa, uma diminuição da coesão social.

É mais proveitoso de fato encaminharse para experiências de reparação simbólica ${ }^{29}$ e concreta, para uma indenização econômica dos prejuízos, para a mediação entre vítimas e réus.

Desde sempre o Voluntariado defendeu a eficácia das medidas alternativas à prisão, que demonstraram número de recaídas grandemente inferior de quem cumpre inteiramente a pena na cadeia e demonstraram um custo econômico igualmente inferior para a

\section{REFERÊNCIAS}

1. AA VV: Una vittoria della partecipazione FDI N N $^{\circ}$ 77-78-79, 1981 p.264-266

2. AA.VV.: Ordine \& Disordine; Fondazione Michelucci, Nuova Grafica Fiorentina, Firenze, 2007

3. AA.VV.:Volontari: rapporto sul volontariato italiano in trasformazione, Communitas, Milano, 2007

4. AA.VV. Commissione Interministeriale Giustizia - Salute, Gruppo di lavoro per i problemi degli Ospedali psichiatrici giudiziari (OPG), 2009

5. Bisi R., Faccioli P.: Congli occhi della vittima, Franco Angeli, Milano, 1996

6. Calamandrei P.: Fede nel diritto, Laterza, Bari, 2008 sociedade. As medidas alternativas - sejamos claros! - não podem considerar-se favores assistenciais; ao contrário representam verdadeiras penas com obrigações, prescrições, restrições, mas sem aquele excesso da violência das instituições. Por estas medidas poder-seiam reintegrar milhares de detentos culpados de leves crimes, poder-se-iam ampliar os trabalhos socialmente úteis e, através da redução dos internados, poder-se-ia melhorar a situação carcerária.

Os voluntários da Justiça ${ }^{30}$, a cada dia, encontram histórias de "vidas queimadas", cortantes como uma faca afiada, pelas quais infelizmente não têm perspectiva de mudança e de melhora no interior da prisão ou do hospital psiquiátrico. ${ }^{31}$ Mas esta constatação não nos deprime, ao contrário, fortalece o nosso desejo de restituir o futuro e a dignidade a muitas pessoas. È um desejo que encontra outros partidários - os profissionais, as associações, os políticos, os cidadãos - que se empenham para mudar a tragédia do presente e que não querem - como nós - estar forçados, um dia, a envergonhar-se do próprio silêncio.

7. Comitato contro l'emarginazione di Vetralla: Contro il manicomio Giudiziario, FDI Nº71- 71, 1981 p.33-34

8. Dell'Acqua G., Mezzina R.: Il folle gesto, Perizia psichiatrica, manicomio giudiziario, carcere nella pratica dei servizi di salute mentale a Trieste (197888) Sapere 2000, Trieste, 1988

9. Di Marco G.: Criminalità e follia. Nascita del manicomio criminale in Italia FDI N²0, 1975 p. 102-122

10. Fondazione Michelucci, Regione Toscana: Non Cancellatemi, Parole colori e interpreti dell'Ospedale Psichiatrico Giudiziario di Montelupo Fiorentino, Pontecorboli Editore, Firenze 1994,

11. Giannichedda M.G., Grassi L.: Il manicomio giudiziario: problemi e proposte per il suo superamento FDI $\mathrm{N}^{\circ}$ 91-92, 1983 p.73-87 
12. Grossi V.: Per l'abolizione dei manicomi giudiziari: FDI N85-86 1982 p.259-266

13. Iannucci Mario, Brandi Gemma, Rossi Prodi Paolo: Il trattamento del "reofolle”, Salute e territorio $\mathrm{N}^{\circ}$ 153, 2005 p.370-2005

14. Manacorda A.: Il manicomio giudiziario (tesi precongressuale di PD) FDI $\mathrm{N}^{\circ} 27-$ 28, 1976 p.69-73

15. Manacorda A.: Il manicomio giudiziario, anno 1977: riforma o abolizione FDI $\mathrm{N}^{\circ}$ 45, 1978 p.106-120

16. Manacorda A.: Il manicomio giudiziario, De Donato, Bari, 1983

17. Manacorda A. : Folli e reclusi, una ricerca sugli internati negli OPG italiani, La casa Usher, Firenze, 1988

18. Margara A. : Manicomio giudiziario e legge 180, Fogli d'informazione $n^{\circ}$ 5-6 terza serie - 01-06/2008

19. Mathiesen T.: Kan fengsel forsvarses?, Pax Forlag, Oslo, 1987

20. Martini C. M.: Sulla giustizia, Mondadori Saggi, Milano, 1999

21. Michelucci G.: Un fossile chiamato carcere, Pontecorboli ed., Firenze, 1993

22. Ministero Solidarietà Sociale: Volontariato e pianificazione sociale di zona: la partecipazione, Isfol, Roma, 2006
23. Mistura S.: Sul manicomi giudiziario FDI N³9-40, 1977 p.189-195

24. Psichiatria Democratica, Magistratura Democratica, Soccorso Rosso Romano: Psichiatria e giustizia: Inchiesta sui manicomi giudiziari e sui manicomi comuni, Ciclostilato, Roma, 1974

25. Pugliese G., Giorgini G.: Mi firmo per tutti, Dai manicomi criminali agli ospedale psichiatrici giudiziari, un'inchiesta e una proposta, Arci Solidarietà, Data News, Roma, 1997

26. Scarpa F, (a cura): Psichiatria Slegata, atti del convegno ' $L$ 'OPG tra custodia e percorsi di salute, Montelupo 15 maggio 2003, Centro di Documentazione di Pistoia, 2004

27. Teodori M.P.: Ospedale psichiatrico giudiziario: problema sempre aperto, in AA VV: Manicomio ultimo atto CDP 1996, (FDI 170) p.195-199

28. Thiebaut C.: De la tolerancia, Visor Dis, S.A., Madrid, 1999

29. Valcarenghi M.: I manicomi criminali, Mazzotta, Milano, 1975

30. Wacquant L.: Punire i poveri.Il nuovo governo dell'insicurezza sociale, Derive Approdi, Roma, 2006

31. Zatti P., Infermità di mente e diritti fondamentali della persona, in Politica del diritto, a. XVII, n. 3, settembre 1986.

Recebido em 22 de agosto de 2009.

Modificado em 02 de janeiro de 2010.

Aceito em 30 de janeiro de 2010. 